\title{
A Holistic Method for Conductor Ampacity and Sag Computation on an OHL Structure
}

\author{
Konstantinos Kopsidas, Member, IEEE, Simon M. Rowland, Senior Member, IEEE, and Boud Boumecid
}

\begin{abstract}
The rating current (ampacity) of a conductor erected on a particular overhead line (OHL) structure installed at a specified location is influenced by the conductor, the OHL structure as well as weather and operational parameters. Many studies have been carried out regarding calculating an aerial bare conductor's ampacity at a steady-state conductor temperature, but without considering the OHL structure as part of the system. In this paper, a holistic methodology for calculating the conductor's ampacity and sag at any temperature and power frequency, erected onto a pre-specified OHL structure is developed, considering together the mechanical and electrical parameters of the overall system. This methodology incorporates the conductor's basic material properties allowing the calculations to be applied to newly developed high temperature low sag composite conductors. In this way it becomes possible to identify, at system level, the potential benefits that may result from the improved performance of these conductors as well as to indicate new sizes that may better fit a pre-specified system, optimizing its performance. The methodology is also validated with a real system application, resulting in correct predictions of the performance of a 4-span double line system.
\end{abstract}

Index Terms-Ampacity, bare conductors, conductor creep, overhead line, re-conductoring, re-tensioning, sag, thermal rating.

\section{INTRODUCTION}

$\mathbf{T}$ HE need to increase the power transfer capacity of existing distribution and transmission lines has resulted from the growth in demand for, and generation patterns of, electrical power. However, this is not always easy to achieve in a deregulated environment where competition forces utilities to operate existing lines at maximum rated capacities due to environmental and cost barriers. As a result, utilities may attempt to extract the most out of the installed lines by operating them closer to the thermal limit, and even temporarily exceeding it, causing loss of strength in the conductor and increased sags, leading to higher risk operation and occasional blackouts [1].

An economical method to increase the capacity of an existing system can be achieved by enabling existing lines to operate at higher temperatures. This may infringe groundclearance requirements, but can be accomplished by retensioning the conductor, a technique mainly based on the

Konstantinos Kopsidas (konstantinos.kopsidas@manchester.ac.uk) and Simon M. Rowland (s.rowland@manchester.ac.uk) are with the School of Electrical and Electronic Engineering, The University of Manchester, UK.

Boud Boumecid (boud.boumecid@uk.ngrid.com) is with National Grid Electricity Network Investment Department - Asset Policy, Warwick, UK. increase of the conductor's clearance to the ground by increasing its tension on the power line. This, therefore, will increase the thermal limit of the line since more thermal expansion can be allowed permitting more current to flow through it. Another way to achieve power capacity increase is to replace conductors (re-conductoring) with larger all aluminum alloy conductors (AAAC) or aluminum conductor steel reinforced (ACSR) wire or conductors with new materials which allow higher temperature operation and develop lower sags. The latter are usually referred to as high temperature low sag (HTLS) conductors. Either way the computations for the new maximum current capacity and conductor sag have to be performed for the new conductor which will become part of the existing OHL system.

The paper presents a holistic methodology that allows evaluation of the maximum sag and ampacity of a conductor considering its structure and the electro-mechanical properties of its basic materials, as well as OHL structure constraints. Such methodology provides the flexibility to evaluate the performance of non-standard conductors on a pre-specified OHL system. The validation of this methodology with a real system application is also presented.

\section{OVERVIEW OF EXISTING Literature ON SAG-TENSION METHODS}

Many studies have dealt with calculating an aerial bare conductor's sag and ampacity at a steady-state conductor temperature. Most of this work makes use of the widely accepted "ruling span" method of sag-tension calculation for multiple suspension spans. The method provides solutions to the parabolic and hyperbolic equations which define the relationship between span, sag, and tension.

Considerable work on the topic took place during the $1950 \mathrm{~s}$ and 1960s, mainly focusing on graphical and analytical methods for sag-tension calculations [2-4] and methods for the estimation of the current-carrying capacity of ACSR conductors $[5,6]$. A method for sag-tension calculation based on stress-strain and temperature elongation data obtained on ACSR conductors was presented in [7] and had been further extended and developed to a computer program (STESS) for use in transmission line and operation [8]. A similar stressstrain approach is also followed by [9] in an attempt to deal with the limitations of existing methods and software concerning gap-type conductors. Other recent modifications to the methods include a hybrid numerical method to calculate the sag of composite conductors [10] and an "aluminum stress 
method" which allows vibration constraints to be based on specified values of static tensile aluminum stress [11]. There are also commercially available sag-tension programs which give good results for most practical applications [12, 13].

Such methods were initially developed to evaluate the performance of conventional (AAAC and ACSR) conductors also incorporating experimental measurements of existing conductors. Recent research in the area has extended to include novel (HTLS) conductors in such evaluations [14-17]. A comparison of the performance of ACSS with ACSR and aluminum conductors aluminum reinforced (ACAR) is presented in [15] assuming the system is under specific extreme heavy loading conditions. On this specific comparison the ACSS conductor appears to perform better because of the different maximum tension at the heavy load condition [15]. In [16] ACSS, ZTACIR and CTACSR conductors are also compared with ACSRs due to their bimetallic similarities.

Most of the sag-tension methods and packages, even though produce acceptable predictions, are limited to estimating conductors' performance based on data provided by conductors' manufacturers. Hence, they are not flexible to investigate how non-standard conductors will perform. Furthermore limited work has been done to examine conductor performance incorporating the properties of the structure (wood pole or lattice towers) to evaluate the real benefit of different HTLS conductors when compared with ACSRs and AAACs.

In order to progress efficiently to such investigations, a more holistic approach should incorporate along with the weather loading and conductor properties, the system limitations to allow non-conventional conductors (in size and materials) to be evaluated on pre-specified systems. Such considerations are taken into account in the methodology introduced in this paper. This allows the overall performance evaluation of lighter conductor technologies with different sag performance, instead of limiting the comparisons only to conductors' sag performance. Furthermore, re-conductoring scenarios can be investigated considering new technologies and conductors of composite materials and non-standard sizes.

\section{COMPUTATIONAL FrAMEWORK}

\section{A. Outline of the computations}

The current rating of a conductor erected on a particular OHL structure at a specified location is controlled by the weather, the conductor, the OHL structure, and operational conditions. This current rating specifies the maximum power transfer capability of the OHL system. The overall performance of the system is affected by properties that can be divided into three distinct groups: mechanical, electrical and ageing. Consequently, the computations are performed in three levels: mechanical, electrical and ageing. Every level is influenced by the weather, conductor structure and operational conditions. These three distinct computational levels are linked together as shown in Fig. 1 in order to compute the conductor maximum current capacity and maximum sag. The input data are divided into four groups: the OHL support structure data, the weather data, the conductor data, and the operational data.

OHL data describe the structure at the time of installation of the wires. These include the design installation tensile stress of the electrically unloaded conductor, the ambient temperature during the installation, the span length, the type of insulation sets, and the difference between the insulation set attachment levels as well as their heights from the ground. The last three are determined by the support structure (i.e. lattice tower or wood pole) of the OHL system.

The weather data include the ice thickness, ice density, and the wind speed at a given ambient temperature which define the designed maximum weather loading. These data are usually described by weather maps [18-20] or can be derived from historical data. These determine the absolute maximum working tension (AMWT) that the conductors may experience and, therefore, the maximum sag value developed at low temperatures. This group also includes weather data that are used for the current-temperature calculations as described in [21].

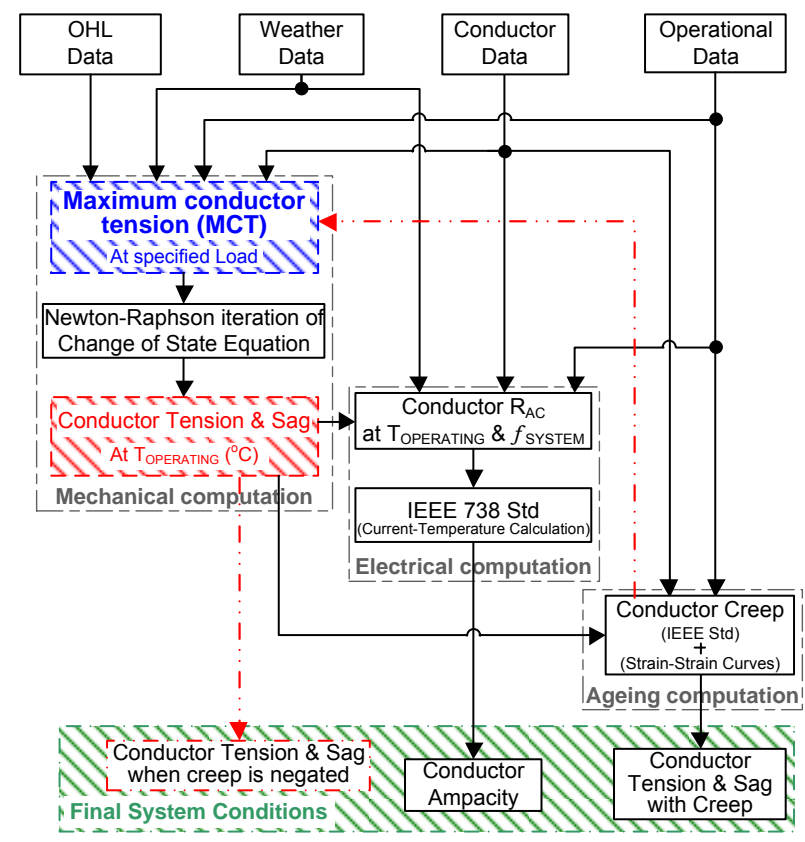

Fig. 1. Flow chart of the computations.

The conductor data involves a conductor's electrical and mechanical properties as well as its physical design. Most basic are the density, modulus of elasticity, coefficient of thermal expansion, tensile strength, conductivity, stranding pattern, grease pattern and density, and type of strands (trapezoidal or cylindrical), as well as their diameter. These are usually provided by conductor manufacturers and are included in relevant standards [22-29] for the most standard conductor types.

The last group, operational data, includes the maximum 
operating temperature of the conductor, system frequency, methodology used (if any) for mitigation of the conductor creep, predicted duration of the maximum conductor operating temperature, designed emergency loading, and duration of operation at the elevated temperature.

Some of the variables that describe the overall structure have to be pre-defined in order to initiate the computations. These variables are the ones that define the weather loading, the maximum operating loading and the OHL structure.

The methodology summarized in Fig. 1 and detailed in subsequent sections can then be used to calculate and compare the electrical and mechanical performance of different conductors for the same OHL structure and identify the most suitable for the particular structure. Changes in the OHL structure cause changes in the performance of the same conductor, as do weather changes (e.g. maximum ambient temperature, maximum wind speed, ice loading etc.).

Fig. 1 also shows that the computations at the ageing level are performed at the end in order to calculate the final conductor sag. This computation level can also be used to evaluate the increase of initial conductor tension that is needed to balance the plastic strain of the conductor. Furthermore, if pre-tensioning of the conductor is considered in the initial input data (affecting the OHL and conductor data groups) this part may be omitted, for simplification, and the final system condition would be the conductor sag calculated at the mechanical level with the same conductor ampacity. However, conductor pre-tensioning may not be permitted by the strength of the support structure.

\section{B. Mechanical computations}

This mechanical part of the computations is performed to calculate the conductor sag and tension at the designed maximum operating temperature of the conductor $\left(\mathrm{T}_{\mathrm{MAX}}\right)$. In order to achieve this, the maximum conductor tension (MCT) of the specified OHL system is required.

The MCT (i.e. the maximum working tension of the conductor on a particular OHL system) is controlled by the following limitations that are generally applied in any structure:

- The maximum permitted tension allowed by the weakest system component which may be the insulator pin or the insulator or the tower/pole structure. This tension limit is defined in the calculations as the structure maximum working tension (SMWT).

- The self-damping vibration limit tension of the conductor, effectively defines the everyday tension (EDT) at a specified conductor temperature. This limit is usually employed to reduce the aeolian vibrations to an acceptable level [20], and determines the conductor's vibration limited maximum working tension (VLMWT).

- The absolute conductor working tension (ACWT) for the specified weather loading, for example $50 \%$ of the conductor rated breaking strength (RBS) at $-5.6{ }^{\circ} \mathrm{C}$ with combined wind and ice [20,29]. The weather (ice and wind) loading and the minimum temperature of the conductor influence the MCT since they affect the elastic (weight) and thermal (temperature) elongation of the cable.

The procedure to determine the MCT of the power line design is illustrated in Fig. 2. Initially, the weather loading conditions of a power line (for example load cases 1 to 6 in $[29,30])$, are identified by its location and the help of weather maps [20, 29] or historical data. The weather loading conditions also define the corresponding safety factors (SF) [29-31]. These safety factors are applied to the conductor and the structure (insulator/insulator pin) and the smallest maximum allowable tension of these is set as the absolute maximum working tension (AMWT) of the conductor applied on the specified system (Fig. 2).

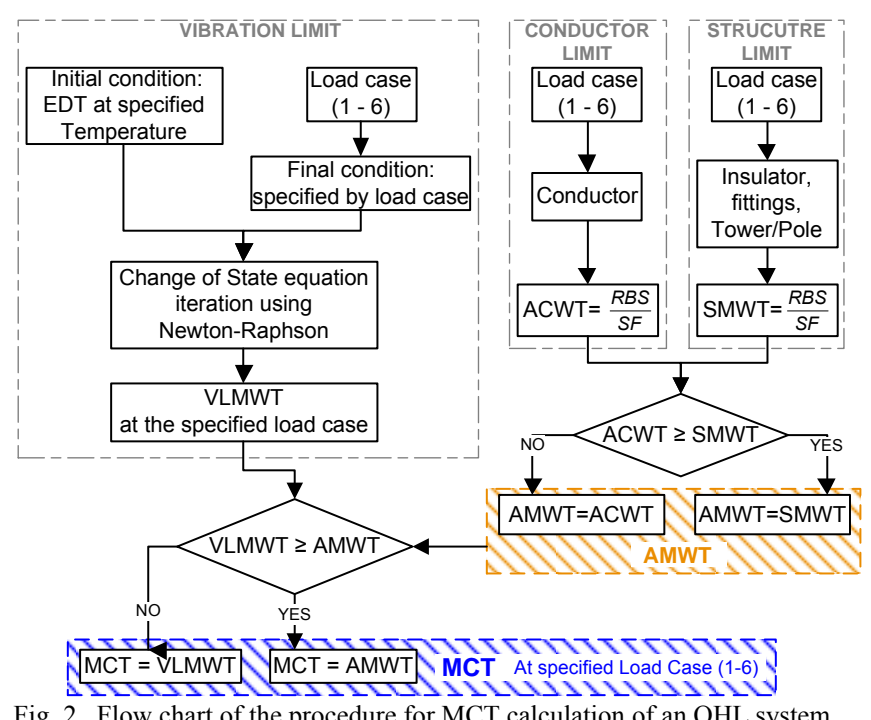

Fig. 2. Flow chart of the procedure for MCT calculation of an OHL system.

The Newton-Raphson iteration method is employed on the change of state equation (1), derived from the catenary curve. In (1) the elastic and thermal elongations of the conductor are included with the plastic elongation computed separately since the latter is affected by the operating conditions [32].

$$
\begin{aligned}
\mathrm{f}\left(F_{H F}\right) & =\frac{2 \cdot F_{H F}}{W_{F}} \sinh \left(\frac{W_{F} \cdot \ell}{2 \cdot F_{H F}}\right) \\
& -\frac{2 \cdot F_{H I}}{W_{I}} \sinh \left(\frac{W_{I} \cdot \ell}{2 \cdot F_{H I}}\right) \cdot T h \cdot E l=0
\end{aligned}
$$

With:

$$
\begin{aligned}
& T h=\left[1+\varepsilon \tau_{C}\left(T_{F}-T_{I}\right)\right] \text { (Thermal elongation) } \\
& E l=\left[1+\frac{\left(F_{H F}-F_{H I}\right)}{E_{C} \cdot A_{C}}\right] \text { (Elastic elongation) }
\end{aligned}
$$

where subscripts $F$ and $I$ define the final and initial conditions respectively and: 
$F_{H}=$ Horizontal conductor tensile force

$W=$ Resultant conductor weight per unit length

$\ell \quad=$ Span length

$T=$ Conductor temperature

$\varepsilon \tau_{C}=$ Conductor's coefficient of thermal expansion

$E_{C}=$ Conductor modulus of elasticity

$A_{C}=$ Conductor cross sectional area

The everyday tension (i.e. the design stress in the unloaded conductor that is applied to minimize the aeolian vibrations of the conductor at a designed temperature) and the conductor weight are set as initial conditions while the final condition is the conductor resultant weight (i.e. the vectorian sum of the conductor, wind, and ice weight) and the VLMWT at the maximum designed weather loading.

The output VLMWT of this iteration is then compared with the AMWT and the smallest one defines the MCT of the OHL system at the specified weather loading.

Once the MCT is known then a second Newton-Raphson iteration of (1) takes place with initial conditions the MCT of the OHL system and the conductor resultant weight (i.e. the sum of the conductor, wind, and ice weight) at the maximum designed weather loading temperature, in order to identify the conductor tension at any operating temperature $\mathrm{T}_{\text {OPERATING }}$ (Fig. 1). Once the conductor tension at the operating temperature is calculated, the sag is computed by using the catenary curve. The output is then linked with the other two computational parts.

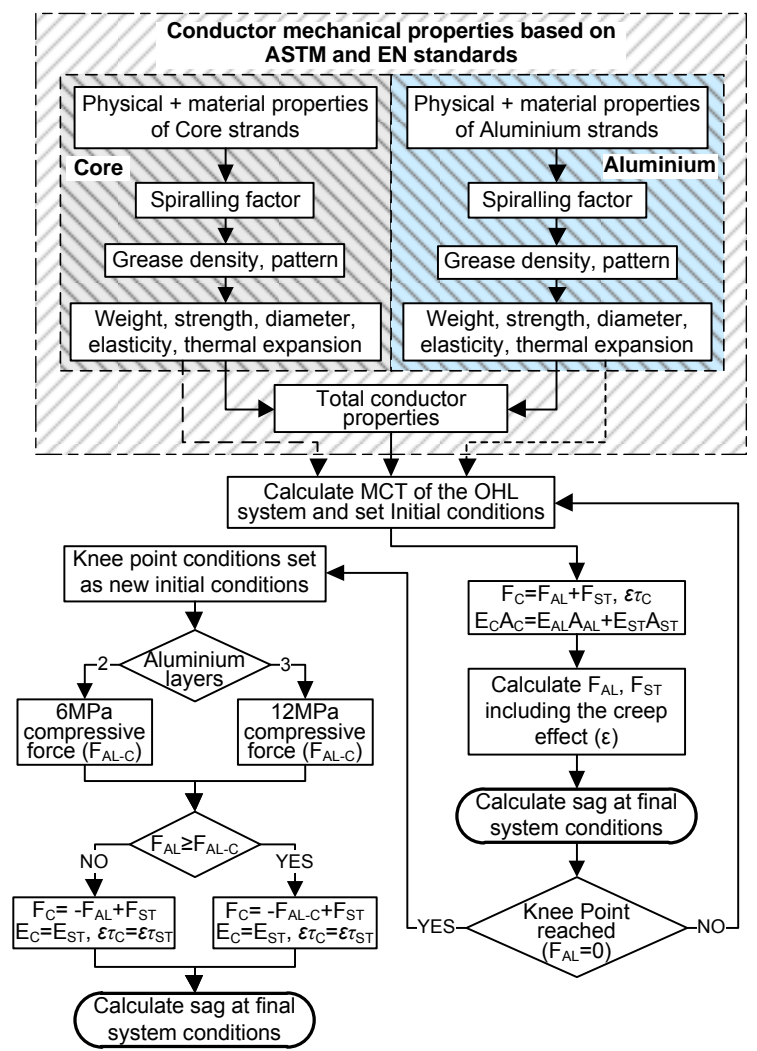

Fig. 3. Flow chart of mechanical computations for the conductor tension and sag at final system conditions.
The MCT computation (described in Fig. 2) is performed based on the conductor design and material properties as illustrated in Fig. 3. This condition is set as a reference point and then using (1) the final tension and sag can be evaluated at different temperatures with an iteration process using small $\left(1^{\circ} \mathrm{C}\right)$ temperature steps. The aluminum and steel tensions are computed from the conductor tension incorporating the conductor creep. The iteration continues up to the knee point, which defines the temperature at which the aluminum contributes zero force to the conductor. The tension and sag at this point are then set as initial conditions to perform calculations for temperatures above the knee point. A new iteration takes place to evaluate the final tension and sag conditions above this point. This is performed using a modified version of (1) in which the conductor properties $\left(E_{C}\right.$, $\left.\varepsilon \tau_{C}, A_{C}\right)$ that affect the thermal and elastic elongations are replaced with the values that correspond to the conductor's core $\left(E_{S T}, \varepsilon \tau_{S T}, A_{S T}\right)$, since the core defines the elastic and thermal elongations of the equation above the knee point temperatures.

\section{Electrical computations}

The electrical part of the computation is used to calculate the $\mathrm{AC}$ resistance $\left(\mathrm{R}_{\mathrm{AC}}\right)$ of any conductor at any temperature defined in the previous part of the computations instead of using the linear interpolation and the tabulated data in [33] for the standard conductor sizes that is used in [21]. This increases the flexibility in the type and size of conductors that can be examined, since this method is not limited to the conductors included in [33]. It also improves accuracy.

The detailed computations within this step of the process are illustrated in the flowchart of Fig. 4. The basic electrical and physical properties of the materials used for the conductor, as well as the conductor itself are used to calculate the DC resistance $\left(\mathrm{R}_{\mathrm{DC}}\right)$ at $20{ }^{\circ} \mathrm{C}$ based on the conductivity, thermal coefficients, diameter and number of strands, and spiraling factors specified by ASTM for cylindrical and trapezoidal strands [22-29]. For wires of distinct strength (core) and conductive (aluminum) members the $\mathrm{R}_{\mathrm{DC}}$ is calculated separately and every part is then corrected to the operational temperature by using the appropriate temperature coefficients [22]. The overall $R_{D C}$ of the conductor is then computed by considering core and outer conductive member resistances in parallel configuration. When the conductor's core is of same material and shape of strands then the $\mathrm{R}_{\mathrm{DC}}$ is calculated by omitting the core's calculations.

To compute conductor $\mathrm{R}_{\mathrm{AC}}$ the skin factor is calculated based on the physical structure of the conductor. The skin factor calculation is based on work of Dwight [34-36] and Lewis and Tuttle [37] which is further simplified with the use of [38] in the code presented in this paper. The skin factor calculation is performed on both cylindrical and tubular conductor shapes, so as to evaluate the effect of nonconductive core materials on conductors.

A second correction factor for the $\mathrm{R}_{\mathrm{AC}}$ calculations is then applied for cases when steel material is used for the core 
design of the conductor, in order to address the magnetization effect of the core on the conductor's $\mathrm{R}_{\mathrm{AC}}$. This effect is negligible on ACSR conductors with even numbers of aluminum layers [21, 33, 37, 39] and so it is not considered in these cases. For the ACSR conductors with an odd number of aluminum layers however, the magnetization factor is used to accurately calculate the $\mathrm{R}_{\mathrm{AC}}$ (Fig. 4). In the case of singlelayer ACSR the correction method described in [21] is used, while for the three-layer conductors the approach of [39] is employed.

Since the magnetization factor is influenced by current flow through the conductor, an iteration with the use of [21] takes place to correct the calculation as illustrated in Fig. 4. This makes the resistance of steel core conductor technologies dependent on conductor temperature and current flow, unlike other conductor technologies whose resistance is dependent on the conductor temperature.

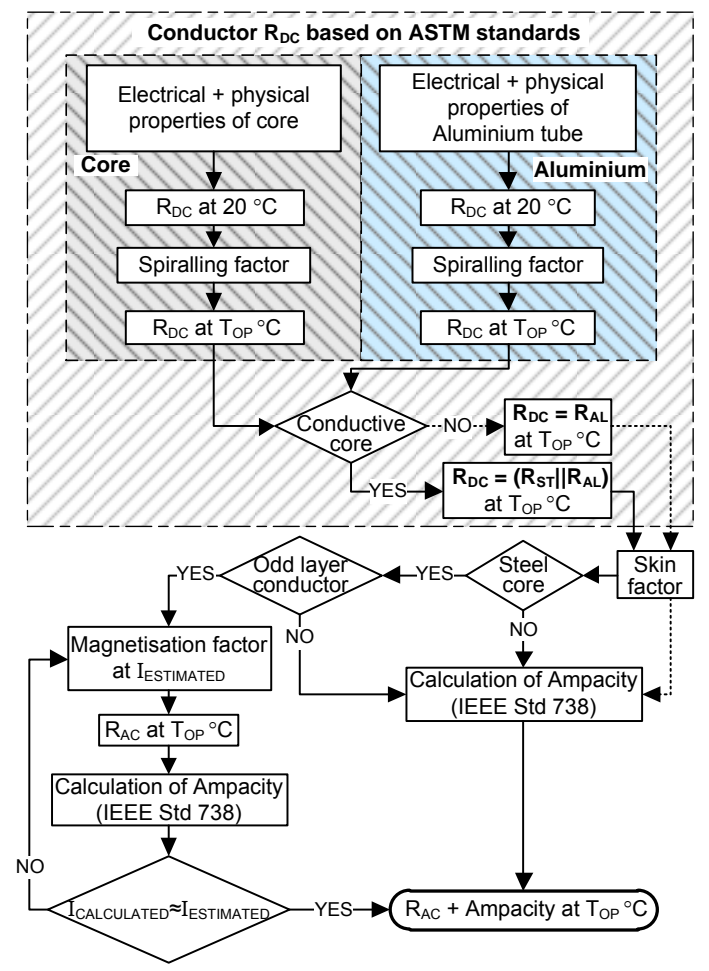

Fig. 4. Synopsis of AC resistance calculation methodology used.

The method described here is employed for calculating the $\mathrm{R}_{\mathrm{AC}}$ of any aluminum alloy conductors (AAC), ACAR, AAAC, and ACSR or any other bimetallic and "bimaterial" conductor technology, type, and size. It can, furthermore, be used for "tubular stranded" conductors or more practically for non-conductive composite core stranded conductors. The difference in the final result of the $\mathrm{R}_{\mathrm{AC}}$ computation between different types of conductors is determined by the $\mathrm{R}_{\mathrm{DC}}$ of the overall cross section area of the conductor, the skin factor, and the magnetization factor differences.

\section{Ageing computations}

Within this part of the computation the non-elastic elongation (i.e. conductor creep) of the conductors under permanent tensile load is calculated for the operating conditions and conductor temperature defined during the mechanical computation part.

Ageing computations are divided into two clusters depending on the type of conductor. The first one regards the well-established conductor types AAC, AAAC, ACAR, and ACSR and the second the recently developed aluminum conductor composite reinforced (ACCR) and aluminum conductor composite core (ACCC) composite conductors [14, 40]. In the first cluster of computations the predictor equations of Table I are used under the pre-specified designed operating conditions of the system [41-43]. These conditions are defined as follows:

- EDT and the ambient temperature at which this tension occurs as well as its predicted duration.

- Maximum operating conductor temperature, conductor tension at that temperature and its predicted duration.

- Conductor's MCT at the designed ambient temperature at which this tension occurs and its predicted duration.

The computations include the prediction of elevated temperature creep (Table I) which occurs above $75{ }^{\circ} \mathrm{C}$ for aluminum conductors and $100{ }^{\circ} \mathrm{C}$ for the steel-reinforced conductors [42].

TABLE I

CREEP PREDICTOR EQUATIONS FOR DIFFERENT CONDUCTOR TYPES AT NORMAL AND ELEVATED TEMPERATURES

\begin{tabular}{|c|c|c|c|c|c|c|}
\hline \begin{tabular}{|c|}
$\begin{array}{c}\text { Cond. } \\
\text { type }\end{array}$ \\
\end{tabular} & \multicolumn{3}{|c|}{ Normal Temperature } & \multicolumn{3}{|c|}{ Elevated Temperature } \\
\hline $\mathrm{AAC}$ & \multicolumn{3}{|c|}{$e_{C}=K \sigma^{1.3} t^{0.16}$} & \multicolumn{3}{|c|}{$e_{C}=M T^{1.4} \sigma^{1.3} t^{0.16}$} \\
\hline AAAC & \multicolumn{3}{|c|}{$e_{C}=G \sigma^{1.3} t^{0.16}$} & \multicolumn{3}{|c|}{$e_{C}=0.077 T^{1.4} \sigma^{1.3} t^{0.16}$} \\
\hline ACAR & \multicolumn{3}{|c|}{$e_{C}=\left(0.19+1.36 \frac{A_{A L}}{A_{t o t}}\right) \sigma^{1.3} t^{0.16}$} & \multicolumn{3}{|c|}{$e_{C}=\left(0.0019+0.012 \frac{A_{A L}}{A_{t o t}}\right) T^{1.4} \sigma^{1.3} t^{0.16}$} \\
\hline ACSR & \multicolumn{3}{|c|}{$e_{C}=C(\% R B S)^{1.3} t^{0.16}$} & \multicolumn{3}{|c|}{$\begin{array}{c}e_{C}=0.24(\% R B S)^{1.3} T t^{0.16} \\
\text { For } \frac{A_{S T}}{A_{t o t}}<7.5 \% \\
\text { otherwise can be ignored }\end{array}$} \\
\hline \multicolumn{3}{|c|}{$\begin{array}{l}e_{c}: \text { creep strain }(\varepsilon)(\mathrm{mm} / \mathrm{km}) \\
T: \text { conductor temperature }\left({ }^{\circ} \mathrm{C}\right) \\
t: \text { elapsed time (hours) } \\
\end{array}$} & \multicolumn{4}{|c|}{$\begin{array}{l}\sigma: \text { stress in tension/area }\left(\mathrm{N} / \mathrm{mm}^{2}\right) \\
A_{A L}: \text { aluminum cross-sectional area }\left(\mathrm{mm}^{2}\right) \\
A_{S T}: \text { steel cross-sectional area }\left(\mathrm{mm}^{2}\right)\end{array}$} \\
\hline \multicolumn{2}{|c|}{ Constant } & 7 strands & \multicolumn{2}{|c|}{19 strands } & 37 strands & 61 strands \\
\hline \multicolumn{2}{|c|}{$\mathbf{K}_{1}$} & 1.3600 & \multicolumn{2}{|c|}{1.2900} & 1.2300 & 1.1600 \\
\hline \multicolumn{2}{|c|}{$\mathbf{K}_{2}$} & 0.8400 & \multicolumn{2}{|c|}{0.7700} & 0.7700 & 0.7100 \\
\hline \multicolumn{2}{|c|}{$\mathbf{M}_{1}$} & 0.0148 & \multicolumn{2}{|c|}{0.0142} & 0.0136 & 0.0129 \\
\hline \multicolumn{2}{|c|}{$\mathbf{M}_{2}$} & 0.0090 & \multicolumn{2}{|c|}{0.0090} & 0.0084 & 0.0077 \\
\hline \multicolumn{2}{|r|}{$\mathbf{G}$} & 0.7100 & \multicolumn{2}{|c|}{0.6500} & 0.7700 & 0.6100 \\
\hline \multicolumn{2}{|c|}{$\mathrm{C}_{1}$} & \multicolumn{5}{|c|}{2.400} \\
\hline \multicolumn{2}{|c|}{$\mathrm{C}_{2}$} & \multicolumn{5}{|c|}{1.400} \\
\hline
\end{tabular}

Subscript "1" denotes 1350-H19 strands drawn from hot-rolled rod Subscript "2" denotes 1350-H19 strands drawn from continuous-cast rod

The second cluster of the ageing computation is very similar to the first one but instead of using the well-established 
predictor equations (Table I) adapted from [41], the stressstrain curves produced by testing of the conductors are used in the absence of standard data. It should also be noted that the ageing computations use an iteration process, since the stress is reduced with time as the creep-strain gradually increases.

\section{IMPLEMENTATION OF THE METHODOLOGY ON A REAL OHL SYSTEM}

The methodology described in this paper is used to predict the sag and identify the ampacity of a $400 \mathrm{kV} \mathrm{L} 2$ type lattice tower OHL system after 29 years from the initial installation of the conductor. The system was strung with a twin bundle Rubus AL5 aluminum alloy conductor. The conductor's electrical and mechanical properties are computed using the described methodology.

Table II shows the conditions relevant to the conductor's installation along with the surveyed and predicted sag values after 29 years of the OHL's operation. As can be observed, the sag prediction is very good and the calculated creep for the 29 years is 597.2 microstrains $(\mu \varepsilon)$. The differences in span lengths between the left and right circuits in the first and fourth spans are due to the use of angle towers at the tension points. This difference in tower type results in non-parallelism of the contiguous tower cross-arms, and therefore, in different conductor span lengths for the right and left circuits.

TABLE II

SURVEYED Data VALUES OF THE $400 \mathrm{KV}$ OHL SySTEM AND PREDICTED SAG

\begin{tabular}{|c|c|c|c|c|}
\hline $\begin{array}{c}\text { Initial Stringing } \\
\text { details }\end{array}$ & \multicolumn{4}{|c|}{$\begin{array}{l}\text { Ruling Span }=340.74 \mathrm{~m} \\
\text { nsion }=39.78 \mathrm{kN}(4056 \mathrm{kgf}) \text { at } 5^{\circ} \mathrm{C}\end{array}$} \\
\hline $\begin{array}{l}\text { Survey conductor } \\
\text { temperature }\end{array}$ & \multicolumn{4}{|c|}{$\begin{array}{cc}\text { Left circuit } & \text { Right circuit } \\
29.06^{\circ} \mathrm{C} & 28.67^{\circ} \mathrm{C} \\
\end{array}$} \\
\hline Span number & 1 & 2 & 3 & 4 \\
\hline Tower Type & DT45 & $\mathrm{D}$ & $\mathrm{D}$ & D30 \\
\hline \multicolumn{5}{|c|}{ Surveyed sag values } \\
\hline Span Length (m) & 318.2311 .8 & 258 & 412 & $322.6 \quad 320.8$ \\
\hline Survey Sag $(\mathrm{m})$ & $7.34 \quad 7.00$ & $4.78 \quad 4.84$ & $12.12 \quad 12.29$ & $\begin{array}{ll}7.48 & 7.49 \\
\end{array}$ \\
\hline \multicolumn{5}{|c|}{ Calculated predicted sag values } \\
\hline Predicted Sag $(\mathrm{m})$ & $7.37 \quad 7.06$ & $4.84 \quad 4.85$ & $12.32 \quad 12.34$ & $\begin{array}{ll}7.57 & 7.47 \\
\end{array}$ \\
\hline Error* $(\mathrm{cm})$ & 6 & 6 & 20 & -2 \\
\hline Sag at $75^{\circ} \mathrm{C}(\mathrm{m})$ & $9.17 \quad 8.82$ & 6.04 & 15.40 & $9.44 \quad 9.33$ \\
\hline Creep $(\mu \varepsilon)$ & \multicolumn{4}{|c|}{597.2 [or $25.96^{\circ} \mathrm{C}$ equivalent thermal elongation ] } \\
\hline
\end{tabular}

*Difference between the measured sag and the calculated predicted values.

TABLE III

INPUT SURVEYED DATA FOR THE CURRENT FLOW CALCULATIONS

\begin{tabular}{|c|c|c|c|}
\hline \multirow{13}{*}{ 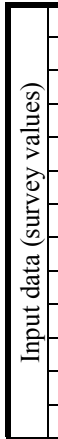 } & OHL Circuit & Left & Right \\
\hline & Wind Speed $\left(V_{\mathrm{W}}\right)$ & \multicolumn{2}{|c|}{$3.27 \mathrm{~m} / \mathrm{s}$} \\
\hline & Wind direction & \multicolumn{2}{|c|}{$15.23^{\circ}$} \\
\hline & Emissivity $(\varepsilon)$ & \multicolumn{2}{|c|}{0.5} \\
\hline & Solar Absorptivity $(\alpha)$ & \multicolumn{2}{|c|}{0.5} \\
\hline & Average Conductor Elevation $\left(\mathrm{H}_{\mathrm{e}}\right)$ & \multicolumn{2}{|c|}{$100 \mathrm{~m}$} \\
\hline & Azimuth & \multicolumn{2}{|c|}{$43^{\circ}$} \\
\hline & Latitude & \multicolumn{2}{|c|}{$52^{\circ}$} \\
\hline & Day of the year & \multicolumn{2}{|c|}{199} \\
\hline & Time & \multicolumn{2}{|c|}{$12: 36$} \\
\hline & Ambient air Temperature $\left(\mathrm{T}_{\mathrm{A}}\right)$ & \multicolumn{2}{|c|}{$21.9^{\circ} \mathrm{C}$} \\
\hline & Solar radiation & \multicolumn{2}{|c|}{$929 \mathrm{~W} / \mathrm{m}^{2}$} \\
\hline & Operating Conductor Temperature $\left(\mathrm{T}_{\mathrm{OP}}\right)$ & $29.06^{\circ} \mathrm{C}$ & $28.67^{\circ} \mathrm{C}$ \\
\hline & Surveyed current & $279 \mathrm{~A}$ & $248 \mathrm{~A}$ \\
\hline & Calculated predicted current & $294 \mathrm{~A}$ & $263 \mathrm{~A}$ \\
\hline
\end{tabular}

The ampacity calculations at the surveyed operating conductor temperatures resulted in similar values as those given by the survey data for both circuits as illustrated in Table III. The sag at $75^{\circ} \mathrm{C}$ (maximum electrical loading) is also calculated (Table II) and the catenary curve of the most critical span of this OHL system is fitted on the conductor (surveyed) sag profile. This is illustrated in Fig. 5 and as can be seen the conductor preserves the $7.6 \mathrm{~m}$ of phase to ground required clearance $[30,44]$. This, therefore, allows for higher operating conductor temperatures without the requirement of re-tensioning the conductor. Consequently, it allows increasing the line's thermal rating, but with an increase in conductor creep that will be caused by the elevated operating temperature according to [41]. In order to compute the new maximum operating temperature (and therefore the system's ampacity) the calculations should be performed again from the beginning and the estimated amount of hours that the line would operate above the $75^{\circ} \mathrm{C}$ should also be specified. This step is important since the elevated conductor temperature could affect the conductor ageing, and thus, the ground clearance after a long period of the conductor in service.

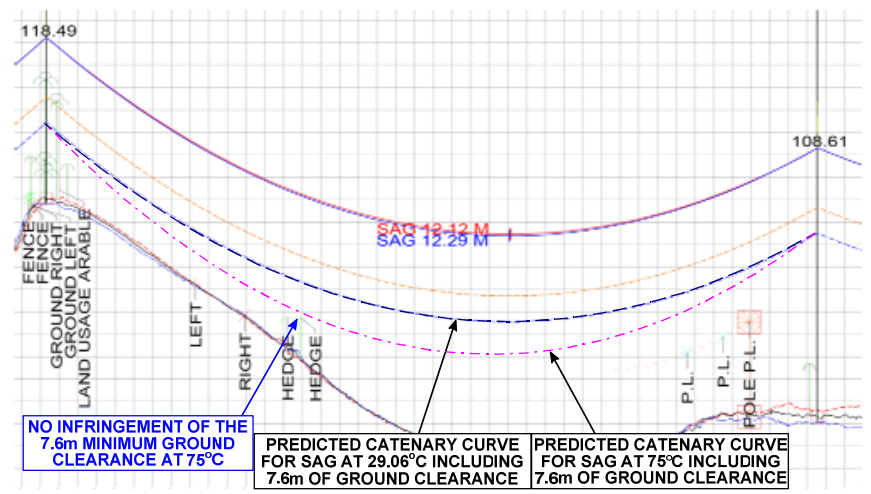

Fig. 5. Surveyed profile of the critical span complemented with calculated catenary curves at surveyed and maximum electrical loading temperatures.

\section{General Application of the Methodology}

The methodology discussed here links the conductor properties with the properties defining the OHL structure in a way that allows investigation of the benefits afforded by uprating techniques such as re-tensioning and re-conductoring as illustrated in the flowchart in Fig. 6. It can also be used to evaluate the improvement in performance that different conductor sizes and/or types may result in, and compare this with different conductors and system operating conditions on a pre-specified OHL system (Fig. 6). Hence, it allows the overall performance evaluation of lighter conductor technologies having different sag performance on a specified system, rather than comparing only their sag performances.

The methodology can then be used to compare the electrical and mechanical performance of different conductors for the same OHL structure and identify the one that allows more electrical power to be transferred through the specified structure and evaluate the losses. Changes in the OHL structure cause changes in the system and thus the 
performance of the same conductor would be different. Weather changes (e.g. ambient temperature, maximum wind speed etc.) also influence the performance of the overall system.

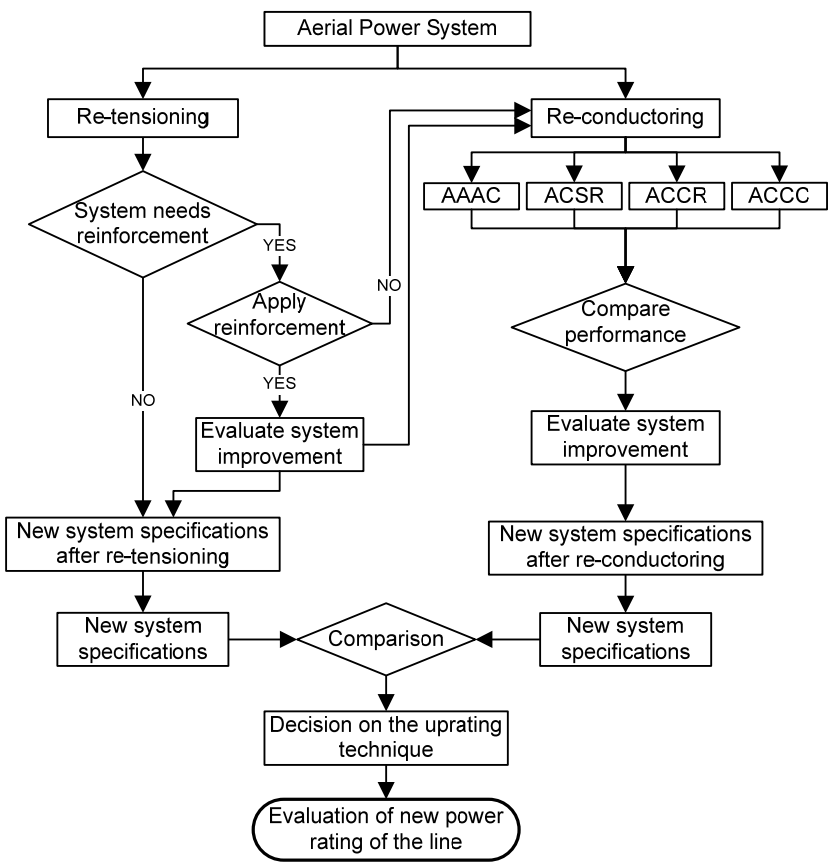

Fig. 6. Flowchart for choosing the appropriate technique for uprating the thermal limit of an aerial power system.

This methodology can be used to identify the effect of increase in operating temperature as well as the impact of vibration dampers on the conductor or the effect of increases in ambient temperature (due to global warming) [45]. Furthermore, it can be used to identify the effect of changes on the OHL design (i.e. increasing the height of the conductor attaching points or their maximum tensile strength). It can also compute the additional creep effect caused by the initial overtension applied to negate conductor's plastic deformation.

The electrical computation section addresses all the bimetallic conductors and with small modifications in the spiraling factors, skin effect and magnetization factor it can also be used for composite core conductors with or without conductive cores (i.e. the conductors in [40] and [14]). Consequently, it increases the flexibility of the calculations at any temperature for any conductor technology and design (even for those for which the properties are known but which are still not fully developed), and allows the direct comparison of the performance of different conductor sizes and technologies on the same OHL structure. For example, modeling the performance of different non existing $\mathrm{ACCC} / \mathrm{TW}$ core to aluminum ratio conductors can be performed to find the optimal fit for a particular OHL system at a given location.

This methodology has already been used to show how different conductor technologies behave in standard UK OHL structures [45] highlighting the potential of re-conductoring with novel HTLS conductors.

\section{CONCLUSIONS}

The current rating and sagging performance of a conductor erected on an OHL structure are influenced by the weather, the conductor and its installation method, the OHL structure, and operational conditions. The methodology presented in this paper links all these parameters together in order to evaluate the actual performance of a conductor on a pre-specified structure. It allows performance comparison of different conductor types and sizes on the same structure. This is important since, in some cases, the structure limits the conductor's performance. The accuracy of this methodology in predicting conductor sag and current flow is also evaluated. The validation process with a 4-span double line system resulted in correct predictions for the 29 years operation time.

The main contribution of this methodology is the flexibility on calculating the conductor properties rather than getting them from a database as well as incorporating OHL structure constraints (weight and tension). It can be used, to evaluate potential uprating by re-conductoring, and increased temperature of operation by re-tensioning on a given line. Furthermore, it can help with the choice of the most suitable conductor for a given system and thus identify the best option in terms of conductor size and technology type, suggesting new conductor designs/sizes.

\section{ACKNOWLEDGEMENT}

This work is funded through the EPSRC Supergen V, UK Energy Infrastructure (AMPerES) grant in collaboration with UK electricity network operators working under Ofgem's Innovation Funding Incentive scheme; full details on http://www.supergen-amperes.org

\section{REFERENCES}

[1] V. T. Morgan, "The Loss of Tensile Strength of Hard-Drawn Conductors by Annealing in Service," IEEE Transactions on Power Apparatus and Systems, vol. PAS-98, pp. 700-709, 1979.

[2] P. F. Winkelman, "Sag-Tension Computations and Field Measurements of Bonneville Power Administration," Power Apparatus and Systems, Part III. Transactions of the American Institute of Electrical Engineers vol. 78, pp. 1532 - 15471960.

[3] T. P. Harley, "A Direct Method for Sag-Tension Calculations," Transactions of the American Institute of Electrical Engineers Power Apparatus and Systems, vol. 72, pp. 603-608, 1953.

[4] M. Landau, "Incremental Method for Sag-Tension Calculations," Transactions of the American Institute of Electrical Engineers, vol. 70, pp. 1564-1571, 1951

[5] H. E. House and P. D. Tuttle, "Current-carrying capacity of ACSR," Power Apparatus and Systems, Part III. Transactions of the American Institute of Electrical Engineers vol. 77, pp. 1169 - 1173, 1959.

[6] J. H. Waghorne and V. E. Ogorodnikov, "Current carrying capacity of ACSR conductors," Transactions of the American Institute of Electrical Engineers, vol. 70, pp. 1159 - 1162, 1951.

[7] O. Nigol and J. S. Barrett, "Characteristics of ACSR Conductors at High Temperatures and Stresses," IEEE Transactions on Power Apparatus and Systems, vol. PAS-100, pp. 485-493, 1981.

[8] J. S. Barrett, S. Dutta, and O. Nigol, "A New Computer Model of ACSR Conductors," IEEE Transactions on Power Apparatus and Systems, vol. PAS-102, pp. 614-621, 1983. 
[9] I. Albizu, A. J. Mazon, and I. Zamora, "Flexible Strain-Tension Calculation Method for Gap-Type Overhead Conductors," IEEE Transactions on Power Delivery, vol. 24, pp. 1529 - 1537, 2009.

[10] A. Alawar, E. J. Bosze, and S. R. Nutt, "A hybrid numerical method to calculate the sag of composite conductors," Electric Power Systems Research, vol. 76, pp. 389-394, 2006.

[11] J. S. Barrett and Y. Motlis, "Allowable tension levels for overhead-line conductors," IEE Proceedings of Generation, Transmission and Distribution, vol. 148, pp. 54 - 59, 2001.

[12] Southwire. [Online]. Available: http://www.sag10.com/support/ SupportDocumentation.htm.

[13] A. K. Deb, Powerline Ampacity System: Theory, Modeling, and Applications. London: CRC Press, 2000.

[14] A. Alawar, E. J. Bosze, and S. R. Nutt, "A composite core conductor for low sag at high temperatures," IEEE Transactions on Power Delivery, vol. 20, pp. 2193-2199, 2005.

[15] H. W. Adams, "Steel Supported Aluminum Conductors (SSAC) for Overhead Transmission Lines," IEEE Transactions on Power Apparatus and Systems, vol. PAS-93, pp. 1700-1705, 1974

[16] I. Zamora, A. J. Mazon, P. Eguia, R. Criado, C. Alonso, J. Iglesias, and J. R. Saenz, "High-temperature conductors: a solution in the uprating of overhead transmission lines," in IEEE Power Tech Proceedings, PortoPortugal, 2001, vol. 4, pp. 1-6.

[17] A. G. Exposito, J. R. Santos, and P. Cruz Romero, "Planning and Operational Issues Arising From the Widespread Use of HTLS Conductors," IEEE Transactions on Power Systems, vol. 22, pp. 1446$1455,2007$.

[18] "BS EN 50423-1: Overhead electrical lines exceeding AC $1 \mathrm{kV}$ up to and including AC $45 \mathrm{kV}$ - Part 1: General requirements - Common specifications," British Standards, 2005.

[19] "BS EN 50341-1: Overhead electrical lines exceeding AC 45 kV - Part 1 General requirements - Common specifications," British Standards, 2001.

[20] "ENATS 43-40: Single Circuit Overhead Lines on Wood Poles for Use at High Voltage Up to and Including 33kV," Energy Networks Association Technical Specifications, Issue 2, 2004.

[21] "IEEE Standard for Calculating the Current-Temperature of Bare Overhead Conductors," IEEE Std. 738-2006 (Revision of IEEE Std 7381993), pp. 1-59, 2007.

[22] "ASTM B 193-02: Test Method for Resistivity of Electrical Conductor Materials," Annual Book of ASTM Standards, vol. 02.03, pp. 68-72, 2005.

[23] "ASTM B 230/B 230M-99: Specification for Aluminum 1350-H19 Wire for Electrical Purposes," Annual Book of ASTM Standards, vol. 02.03 , pp. 91-94, 2005.

[24] "ASTM B 231/B 231M-04: Specification for Concentric-Lay-Stranded Aluminum 1350 Conductors," Annual Book of ASTM Standards, vol. 02.03, pp. 95-105, 2005 .

[25] "ASTM B232/B 232M-01: Specification for Concentric-Lay-Stranded Aluminum Conductors, Coated-Steel Reinforced (ACSR)," Annual Book of ASTM Standards, pp. 106-121, 2005.

[26] "ASTM B233-97(2003): Specification for Aluminum 1350 Drawing Stock for Electrical Purposes," Annual Book of ASTM Standards, vol 02.03, pp. 122-125, 2005.

[27] "ASTM B 498/B 498M-98(2002): Specification for Zinx-Coated (Galvanized) Steel Core Wire for Aluminum Conductors, Steel Reinforced (ACSR)," Annual Book of ASTM Standards, vol. 02.03, pp. 218-221, 2005.

[28] "ASTM B 779 - 03: Standard Specification for Shaped Wire Compact Concentric-Law-Stranded Aluminum Conductors, Steel Reinforced (ACSR/TW)," Annual Book of ASTM Standards, vol. 02.03, pp. 309314, 2005.

[29] "BS EN 50182: Conductors for Overhead Lines - Round Wire Concentric Lay Stranded Conductors," British Standards, 2001.

[30] "BS EN 50341-3: Overhead electrical lines exceeding AC 45 kV - Part 3: Set of National Normative Aspects," British Standards, 2001.

[31] "National Electrical Safety Code 2007 Edition," IEEE Std C2-2007, Aug. 2006.

[32] K. Kopsidas, "Modelling Thermal Rating of Arbitrary Overhead Line Systems", PhD Thesis, Dept. of Electrical and Electronic Engineering, The University of Manchester, Manchester, UK, 2009.

[33] L. Kirkpatrick, "Aluminum Electrical Conductor Handbook," Third ed Washington, D.C.: the Aluminum Association, 1989.
[34] H. B. Dwight, "Skin Effect in Tubular and Flat Conductors," AIEE Transactions, vol. 37, pp. 1379-1403, 1918.

[35] H. B. Dwight, "Skin Effect and Proximity Effect in Tubular Conductors," AIEE Transactions, vol. 41, pp. 189-198, 1922.

[36] H. B. Dwight, "A Precise Method of Calculation of Skin Effect in Isolated Tubes," AIEE Transactions, vol. 42, pp. 827-831, 1923.

[37] W. A. Lewis and P. D. Tuttle, "The Resistance and Reactance of Aluminum Conductors, Steel Reinforced," AIEE Transactions, vol. 77, pp. 1189-1215, 1959

[38] F. W. J. Olver, "9. Bessel Functions of Integer Order," in Handbook of Mathematical Functions, M. Abramowitz and I. A. Stegun, Eds. Washington, D. C.: U. S. Dept. Commerce, 1964, pp. 378-385.

[39] B. S. Howington and L. S. Rathbun, "AC Resistance of ACSR Magnetic and Temperature Effects," IEEE Transactions on Power Apparatus and Systems, vol. PAS-104, pp. 1578-1584, 1985.

[40] 3M, "Aluminum Conductor Composite Reinforced Technical Notebook (477 kcmil family) Conductor \& Accessory Testing." [Online]. (2006). Available: http://www.energy.ca.gov/2004_policy_update/documents/ 2004-06-14-workshop/public comments/2004-06-28 3M PART2.PDF.

[41] R. Thrash, A. Murrah, M. Lancaster, and K. Nuckles, "Overhead Conductor Manual," 2nd ed: Southwire, 2007.

[42] "IEEE Guide for Determining the Effects of High-Temperature Operation on Conductors, Connectors, and Accessories," IEEE Std. 1283-2004, pp. 1-28, 2005

[43] "CIGRE SC22 - WG05: Permanent elongation of conductors. Predictor equation and evaluation methods," Electra $N^{\circ} 75$, pp. 63-98, 1981.

[44] "ENATS 43-8: Overhead Line Clearances," Energy Networks Association Technical Specifications, Issue 3, 2004.

[45] K. Kopsidas and S. M. Rowland, "A Performance Analysis of Reconductoring an Overhead Line Structure," IEEE Transactions on Power Delivery, vol. 24, pp. 2248-2256, 2009.

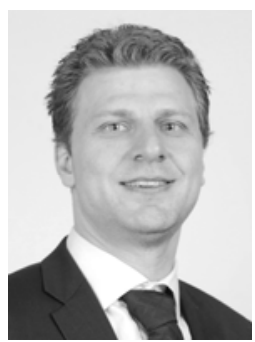

Konstantinos Kopsidas (M'06) was born in Lefkas, Greece. He completed his Higher Technological Education degree in Electrical Engineering from the Institute of Piraeus, Athens, Greece (2002), a B.Eng. degree in Electrical and Electronic Engineering from The University of Manchester Institute of Science and Technology (UMIST), U.K. (2004), an M.Sc. degree with distinction, (2005) and a Ph.D. (2009) in Electrical Power Engineering from The University of Manchester. He had worked as Research Assistant/ Associate on the SuperGen V (AMPerES) and he is now a Lecturer with the School of Electrical and Electronic Engineering in The University of Manchester, also collaborating with Arago Technology. Dr. Kopsidas was awarded the Scottish Power "Power Learning Award" as well as the UMIST course prize twice.

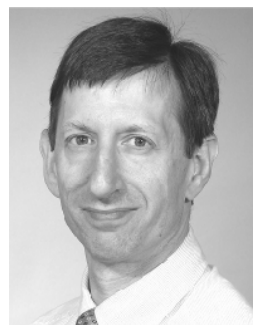

Simon M. Rowland (SM'07) was born in London, England. He completed his B.Sc. degree in Physics at UEA and his Ph.D. degree at London University. He was awarded the IEE Duddell Premium in 1994 and became a FIEE in 2000. He has worked for many years on dielectrics and their applications. He has also been Operations and Technical Director in a multinational manufacturing company. He joined The School of Electrical and Electronic Engineering in The University of Manchester as a Senior Lecturer in 2003

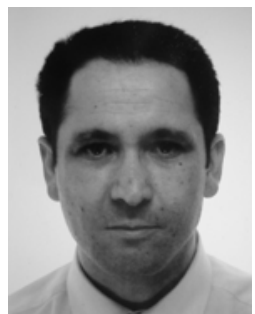

Boud Boumecid, Ing MSc MIET. Received his MSc Degree in Civil Engineering from the University of Salford, Manchester in 1994. He is a Design Engineer (Overhead Lines) in the Electricity Network Investment Department - Asset Policy, National Grid (UK). He is an active member of CIGRE Study Committee SC B2 (WG 23 on Foundations) and BSI - PEL/011 Committee. He has previously worked with Consultants and Contractors where he was involved in the Civil and Structural design of Power Stations, Substations and Overhead Lines. 